\title{
Program Aplikasi Pengolahan Nilai Rapor Siswa pada MDTA Nurul Ikhlas Kabupaten Sukabumi
}

\author{
Hamdun Sulaiman $^{\# 1}$, Indriyanti ${ }^{* 2}$, M. Qomaruddin ${ }^{\# 3}$

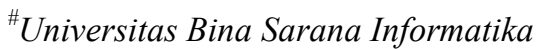 \\ Jl. Kamal Raya No. 18, Ringroad Barat, Cengkareng, Jakarta Barat \\ ${ }^{1}$ hamdun.hslebsi.ac.id \\ ${ }^{3}$ qomaruddin.mqnabsi.ac.id \\ *STMIK Nusa Mandiri Jakarta \\ Jl. Damai No. 8, Warung Jati Barat (Margasatwa), Jakarta Selatan \\ ${ }^{2}$ indriyanti.iytenusamandiri.ac.id
}

\begin{abstract}
Abstrak- MDTA Nurul Ikhlas adalah lembaga pendidikan setingkat sekolah Madarasah Ibtidaiyah (MI) yang terletak di Kabupaten Sukabumi. Untuk mengelola nilai, sekolah tersebut msih menggunakan cara manual dan belum memiliki sebuh sistem informasi. Akibatnya proses pengolahan nilai sering mengalami kendala terutama untuk proses rekap absen, input nilai dari guru, pengolahan nilai oleh wali kelas dan pelaporan terhadap kepala sekolah. Salah satu cara yang dapat dilakukan adalah merancangan sebuah aplikasi sistem informasi pengolahan nilai yang nantinya akan membantu guru untuk meningkatkan kinerjanya dalam setiap penggolahan nilai rapor siswa. Penelitian ini bertujuan untuk merancangan sebuah sistem informasi pengolahan nilai akademik berbasis web yang akan di implementasikan pada MDTA Nurul Ikhlas Sukabumi. Pengembangan sistem perangkat lunak dibuat dengan menggunakan metode waterfall. Hasil penelitian dapat digunakan untuk membantu kinerja guru, sehingga laporanlaporan yang dibutuhkan dapat tersaji secara tepat waktu.
\end{abstract}

Kata kunci-MDTA Nurul Ikhlas, Sukabumi, Aplikasi, Sistem Informasi, Pengolahan Nilai.

\section{Pendahuluan}

MDTA Nurul Ikhlas sebagai salah satu lembaga pendidikan yang berada di Sukabumi, kegiatannya tidak terlepas dari proses kegiatan belajar mengajar. Hasil kegiatan belajar mengajar tersebut berupa nilai yang dlaporkan pada sebuah buku laporan kemajuan belajar siswa atau rapor setiap semesternya. MDTA Nurul Ikhlas menggunakan kurikulum tahun 2010 dengan sistem kompetensi yaitu pengolahan nilai rapor diambil dari laporan keaktifan siswa yang berupa laporan nilai serta informasi mengenai siswa yang bersangkutan. Permasalahan yang terjadi dalam pengolahan nilai rapor di MDTA yaitu penulisan hasil belajar di rapor masih tulis tangan sehingga kurang efektif karena membutuhkan waktu yang lama.
Komputer merupakan mesin penghitung elektronik yang cepat dan dapat menerima informasi input digital, kemudian memrosesnya sesuai dengan program yang tersimpan di memorinya serta menghasilkan output berupa informasi [1]. Dengan bantuan komputer suatu perhitungan akan lebih cepat, pemrosesan data juga lebih cepat, dapat digunakan untuk pengontrolan otomatis, outputnya beragam dan menarik serta tampilannya user friendly [2]. Oleh karena itu, untuk mengatasi permasalahan pengolahan nilai siswa di MDTA Nurul Ikhlas perlu dibangun sebuah sistem komputer untuk membantu dan memudahkan guru dalam mengolah nilai siswa.

Kehidupan manusia pada zaman sekarang tidak dapat lepas dari teknologi, khususnya komputer. Dunia pendidikan khususnya merupakan salah satu yang paling utama yang membawa perubahan tersebut. Bahkan, banyak peralatan berbasis komputer yang sekarang ini umum digunakan masyarakat. Seiring dengan berkembangnya teknologi tersebut manusia pun terus berusaha meningkatkan kreatifitas dan aktifitasnya [12].

Untuk mendukung kinerja guru agar lebih professional dalam melayani siswa, sistem informasi pengolahan nilai diperlukan untuk mempermudah proses pengolahan nilai sehingga tidak memerlukan waktu yang banyak, efisien, cepat dan handal. "Sistem informasi adalah komponenkomponen yang saling berkaitan yang bekerja bersamasama untuk mengumpulkan, mengolah, menyimpan dan menampilkan informasi untuk mendukung pengambilan keputusan, koordinasi, pengaturan analisa dan visualisasi pada sebuah organisasi".[13]

Sistem pengolahan nilai dapat membantu kinerja para guru dan wali kelas untuk melakukan proses pengolahan nilai agar pengelolaan nilai dapat di olah secara efektif dan efisien, sehingga bisa langsung di akses serta informasi (pengumuman) dapat tersampaikan dengan baik.[1] 


\section{LANDASAN TEORI}

\section{A. Konsep Dasar Program}

Pemrograman terstruktur yaitu bentuk pemrograman yang terorganisasi, yang programnya dapat mudah dipahami dan dapat dimodifikasi secara benar [2]. Pembuatan program dapat dilakukan dengan berbagai bahasa pemrograman, salah satunya yaitu Microsoft Visual Basic. Microsoft Visual Basic adalah software untuk membuat progrm berbasis windows. Visual Basic 6.0 memakai bahasa pemrograman BASIC (Beginners All Purpose Symbolic Instruction Code) yang merupakan salah satu bahasa pemrograman tingkat tinggi yang sederhana dan mudah untuk dipelajar [3].

\section{B. Model Waterfall}

Metode yang digunakan pada pengembangan perangkat lunak ini menggunakan model SDLC air terjun (waterfall) [14], yang terbagi menjadi lima tahapan, yaitu:

1. Analisis Kebutuhan

Tahapan ini penulis meneliti kebutuhan sistem yang dibutuhkan sesuai informasi yang didapatkan

2. Desain

Pada tahap ini, untuk dapat ke tahap pembuatan program selanjutnya penulis mengidentifikasi dan menggambarkan abstraksi dasar sistem perangkat lunak dan hubungan-hubungannya.

3. Pembuatan Kode Program

Setelah membuat rancangan desain, penulis akan menterjemahkan semua rancangan desainnya dan mulai pembuatan program yang sesuai dengan rancangan yang telah dipersiapkan.

4. Pengujian

Pada tahap ini, penulis melakukan pengujian program dengan menggunakan pengujian kotak hitam(Black-Box Testing)

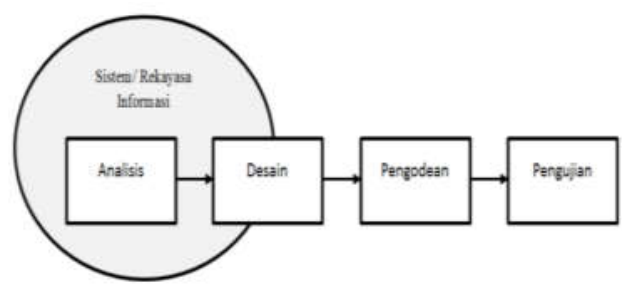

Sumber : Rosa \& Shalahuddin (2013:29) [11]

\section{ERD (Entity Relationalship Diagram)}

Entity Relationship Diagram adalah alat pemodelan data utama dan akan membantu mengorganisasi data dalam suatu proyek ke dalam entitas-entitas dan menentukan hubungan antar entitas [4]. Terdapat tiga notasi dasar yang bekerja pada model E-R, yaitu Entity Sets, Relationship Sets dan Atribut [5].

\section{LRS (Logical Record Structure)}

LRS (Logical Record Structure) merupakan hasil pemodelan Entity Relationship (ER) beserta atributnya sehingga bisa terlihat hubungan-hubungan antar entitas [6]. Terdapat tiga hal yang dapat mempengaruhi dalam pembuatan LRS, yaitu:

- Jika tingkat hubungan (cardinality) satu pada satu (one-toone), maka digabungkan dengan entitas yang lebih kuat (strong entity), atau digabungkan dengan entitas yang memiliki atribut yang lebih sedikit.

- Jika tingkat hubungan (cardinality) satu pada banyak (oneto-many), maka hubungan relasi digabungkan dengan entitas yang tingkat hubungannya banyak.

- Jika tingkat hubungan (cardinality) banyak pada banyak (many-to-many), maka hubungan relasi tidak akan digabungkan dengan entitas manapun, melainkan menjadi sebuah LRS.

\section{E. UML (Unified Modeling Language)}

Unified Modeling Language (UML) adalah bahasa pemodelan utama yang digunakan untuk menganalisis, menentukan dan mendesain suatu sistem perangkat lunak [7]. Ada 9 jenis diagram UML [8], antara lain:

- Diagram kelas

Diagram ini memperlihatkan himpunan kelas-kelas, antarmuka-antarmuka, kolaborasi-kolaborasi, serta relasirelasi.

- Diagram paket

Diagram ini memperlihatkan kumpulan kelas-kelas, merupakan bagian dari diagram komponen.

- Diagram Use-Case diagram ini memperlihatkan himpunan use-case dan aktoraktor (suatu jenis khusus dari kelas).

- Diagram Interaksi dan Sequence

Diagram urutan adalah diagram interaksi yang menekankan pada pengiriman pesan dalam suatu waktu tertentu.

- Diagram Komunikasi

Diagram sebagai penggnati diagram kolaborasi UML 1.4 yang menekankan organisasi struktural dari objek-objek yang menerima serta mengirim pesan.

- Diagram Statechart

Diagrma status memperlihatkan keadaan-keadaan pada sistem, memuat status (state), transisi, kejadian serta aktivitas.

- Diagram Aktivitas

Diagram aktivitas adalah tipe khusus dari diagram status yang memperlihatkan aliran dari suatu aktivitas ke aktivitas lainnya dalam suatu sistem.

- Diagram Komponen

Diagram komponen ini memperlihatkan organisasi serta keberuntungan sistem/ perangkat lunak pada komponenkomponen yang telah ada sebelumnya. 


\section{F. Black Box Testing}

Black Box Testing berfokus pada spesifikasi fungsional dari perangkat lunak. Tester dapat mendefinisikan kumpulan kondisi input dan melakukan pengetesan pada spesifikasi fungsional program. Black Box Testing bukanlah solusi alternatif dari White Box Testing tapi lebih merupakan pelengkap untuk menguji hal-hal yang tidak dicakup oleh White Box Testing [15].

Black Box Testing cenderung untuk menemukan hal-hal berikut:

- Fungsi yang tidak benar atau tidak ada.

- Kesalahan antarmuka (interface errors).

- Kesalahan pada struktur data dan akses basis data.

- Kesalahan performansi (performance errors).

Kesalahan inisialisasi dan terminasi.

\section{PENELITIAN DAN PERANCANGAN SISTEM}

Metodologi pengembangan perangkat lunak dalam penelitian ini:

Metode yang digunakan pada pengembangan perangkat lunak ini menggunakan model SDLC air terjun (waterfall) [14], yang terbagi menjadi lima tahapan, yaitu:

1. Analisis Kebutuhan

Tahapan ini penulis meneliti kebutuhan sistem yang dibutuhkan sesuai informasi yang didapatkan

2. Desain

Pada tahap ini, untuk dapat ke tahap pembuatan program selanjutnya penulis mengidentifikasi dan menggambarkan abstraksi dasar sistem perangkat lunak dan hubungan-hubungannya.

3. Pembuatan Kode Program

Setelah membuat rancangan desain, penulis akan menterjemahkan semua rancangan desainnya dan mulai pembuatan program yang sesuai dengan rancangan yang telah dipersiapkan.

4. Pengujian

Pada tahap ini, penulis melakukan pengujian program dengan menggunakan pengujian kotak hitam(Black-Box Testing).

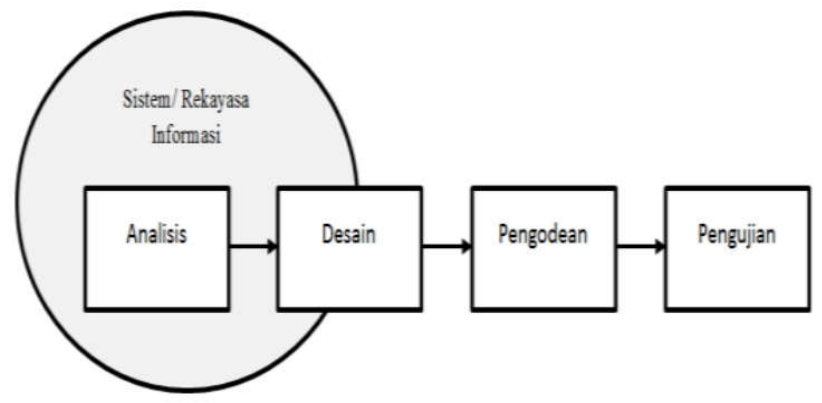

Sumber : Rosa \& Shalahuddin (2013:29) [11]

\section{A. Aanalisis Sistem yang Sedang Berjalan}

Sistem yang sedang berjalan pada MDTA dalam hal pengolahan nilai siswa masih dilakukan secara manual dan belum memiliki sistem atau aplikasi khusus untuk menangani permasalahan tersebut. Nilai yang direkap oleh guru kemudian akan dilaporkan secara manual dan itu membutuhkan waktu yang sangat lama karena mengingat jumlah siswa yang begitu banyak. Hasilnya pun terkadang kurang akurat karena semua perhitungan dilakukan secara manual.

\section{B. Sistem Yang Akan Dibangun}

Berdasarkan analisa sistem berjalan maka diperlukan suatu program aplikasi pengolan nilai rapor siswa. Program aplikasi tersebut dapat memudahkan para guru dalam proses pengolahan nilai rapor siswa dan orangtua siswa bisa lebih cepat untuk mendapatkan laporan nilai hasil belajar siswa. Berikut spesifikasi kebutuhan dari program aplikasi pengolahan nilai rapor siswa:

\section{Halaman Menu Guru:}

- Guru kelas dapat mengolah nilai

- Guru kelas dapat mencetak laporan nilai

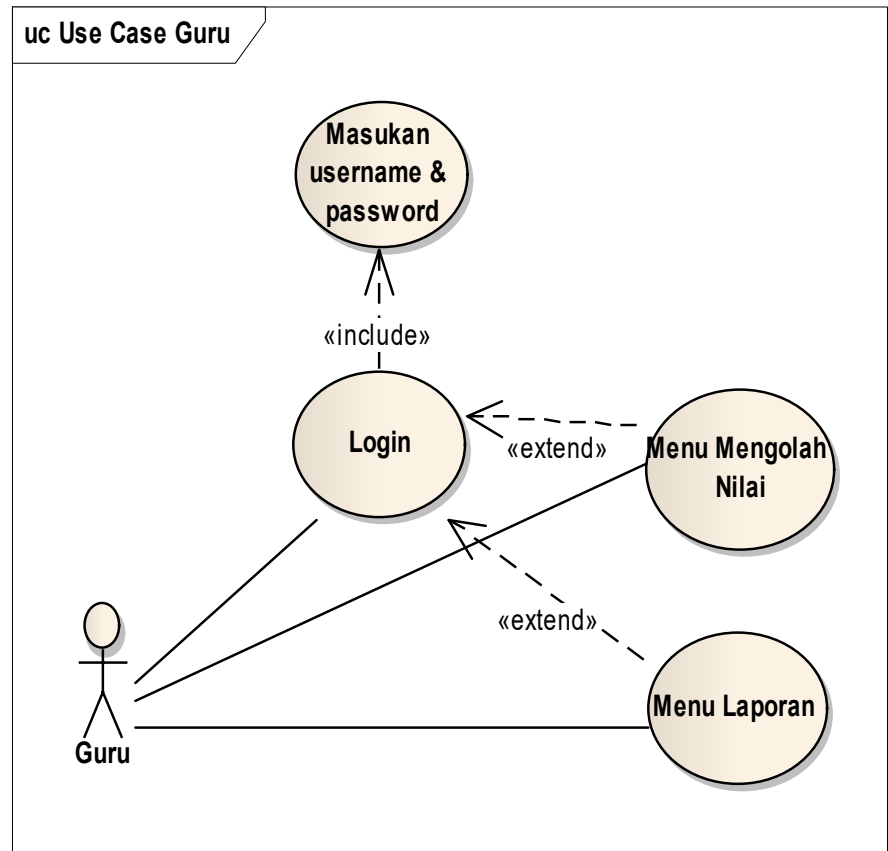

Gambar 1. Use Case Diagram Halaman Guru

Halaman Menu Admin:

- Admin dapat mengolah data guru, data siswa, data pengguna, data pelajaran dan data kelas

- Admin dapat melihat informasi mengenai data yang ada

- Admin dapat mengolah nilai

- Admin dapat mencetak laporan nilai

- Admin dapat membuat surat keterangan 


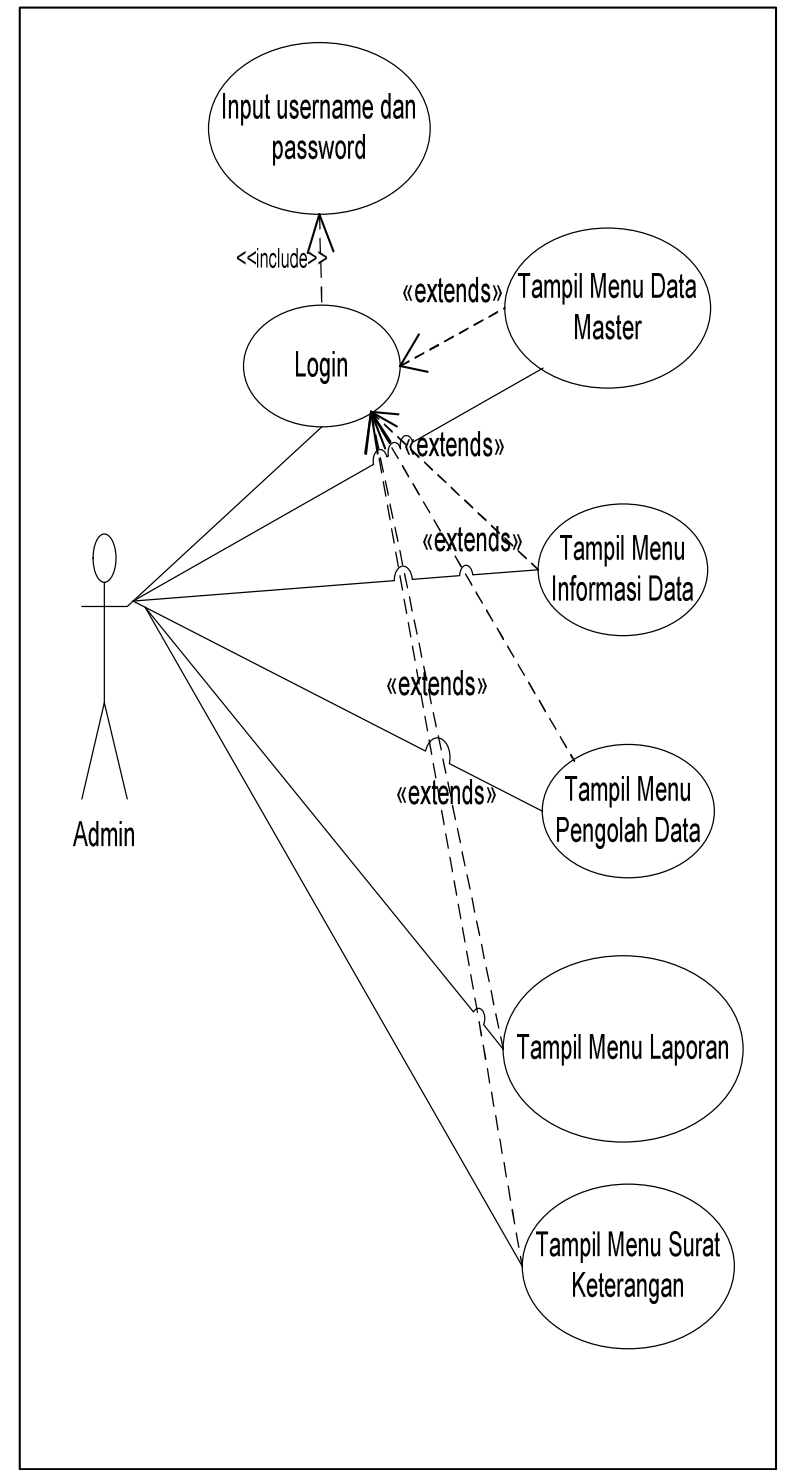

Gambar 2. Use Case Diagram Pengolahan Nilai Halaman Admin
C. Diagram ERD (Entity Relational Diagram)

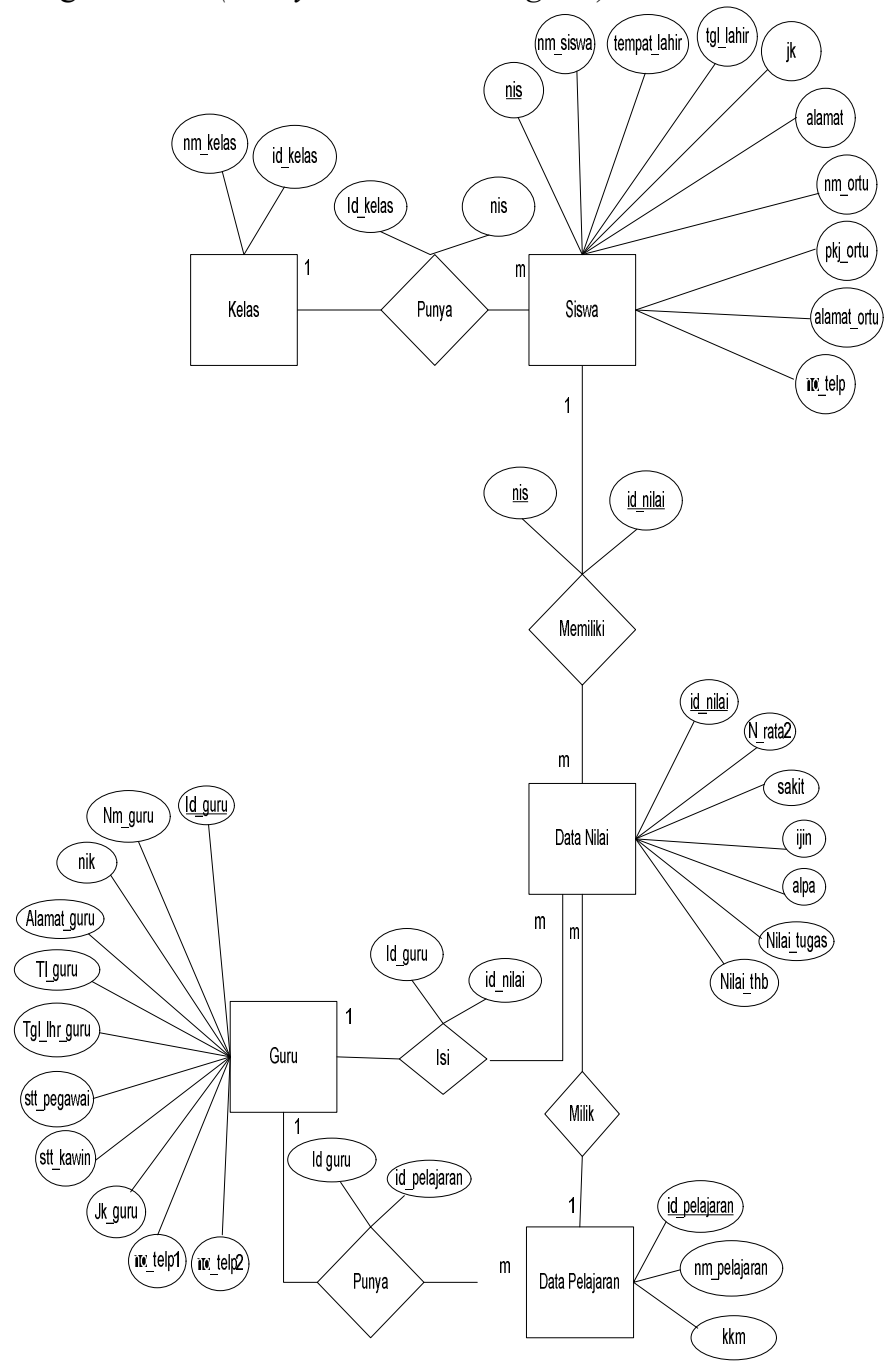

Gambar 4. ERD (Entity Relational Diagram)

D. User Interface

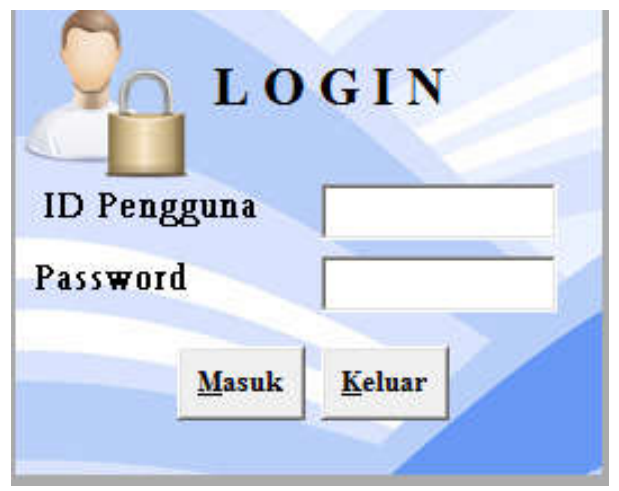

Gambar 5. Tampilan Form Login 


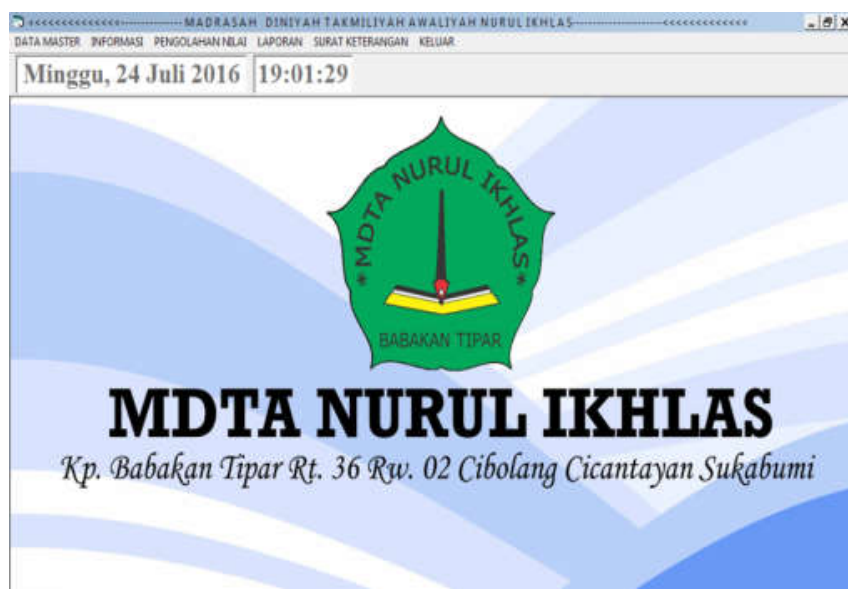

Gambar 6. Tampilan Menu Utama

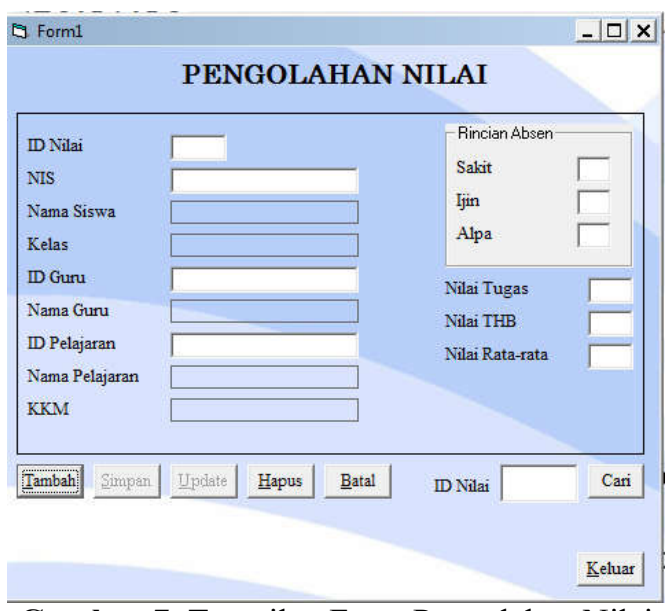

Gambar 7. Tampilan Form Pengolahan Nilai

\section{BUKULAPORAN HASIL BELAJAR SISWA MADRASAH DINIYAH TAKMIIYAH AWALIYAH}

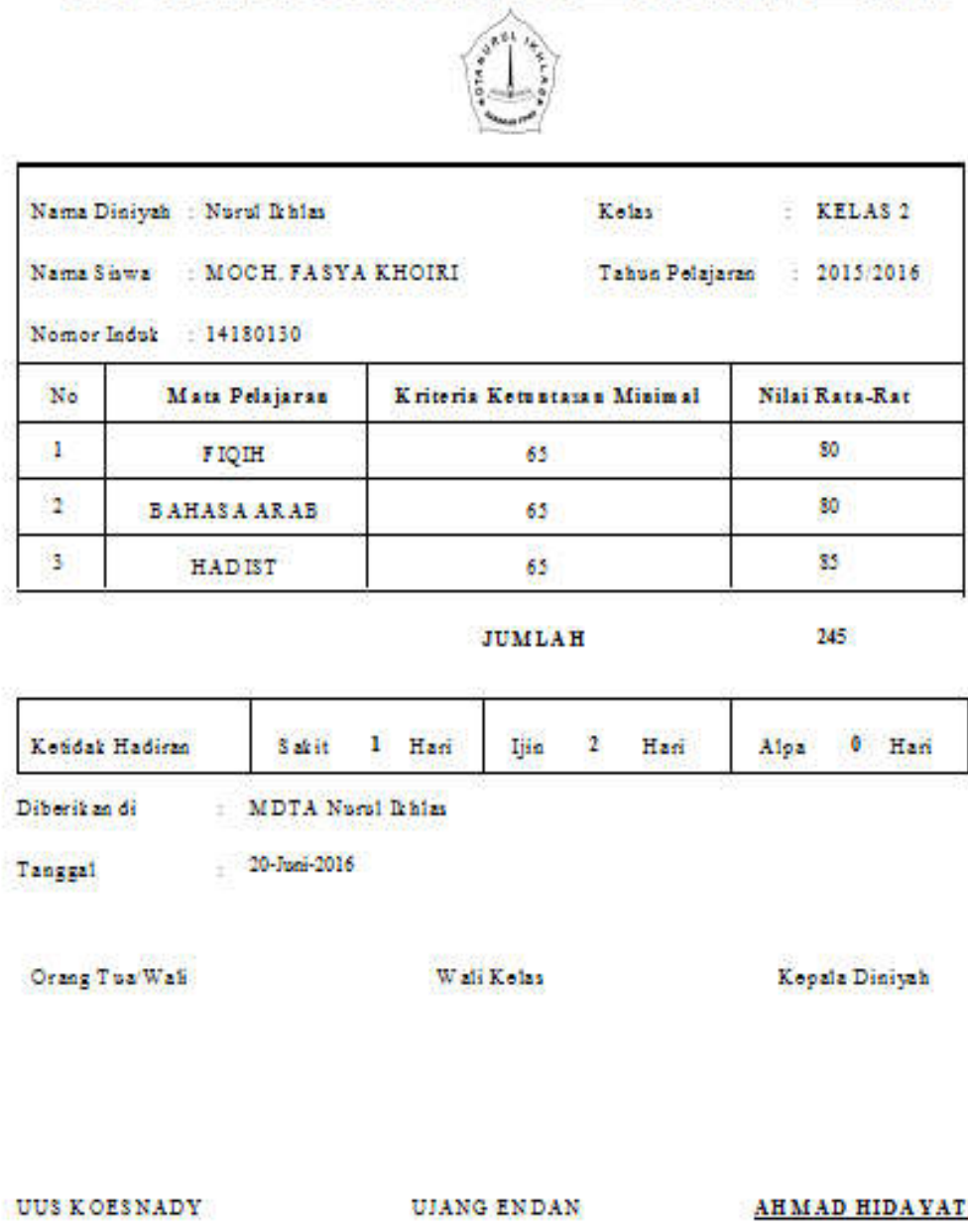

Gambar 8. Tampilan Bukti laporan Nilai 
E. Hasil Pengujian Black Box Testing Form Pengolahan Nilai

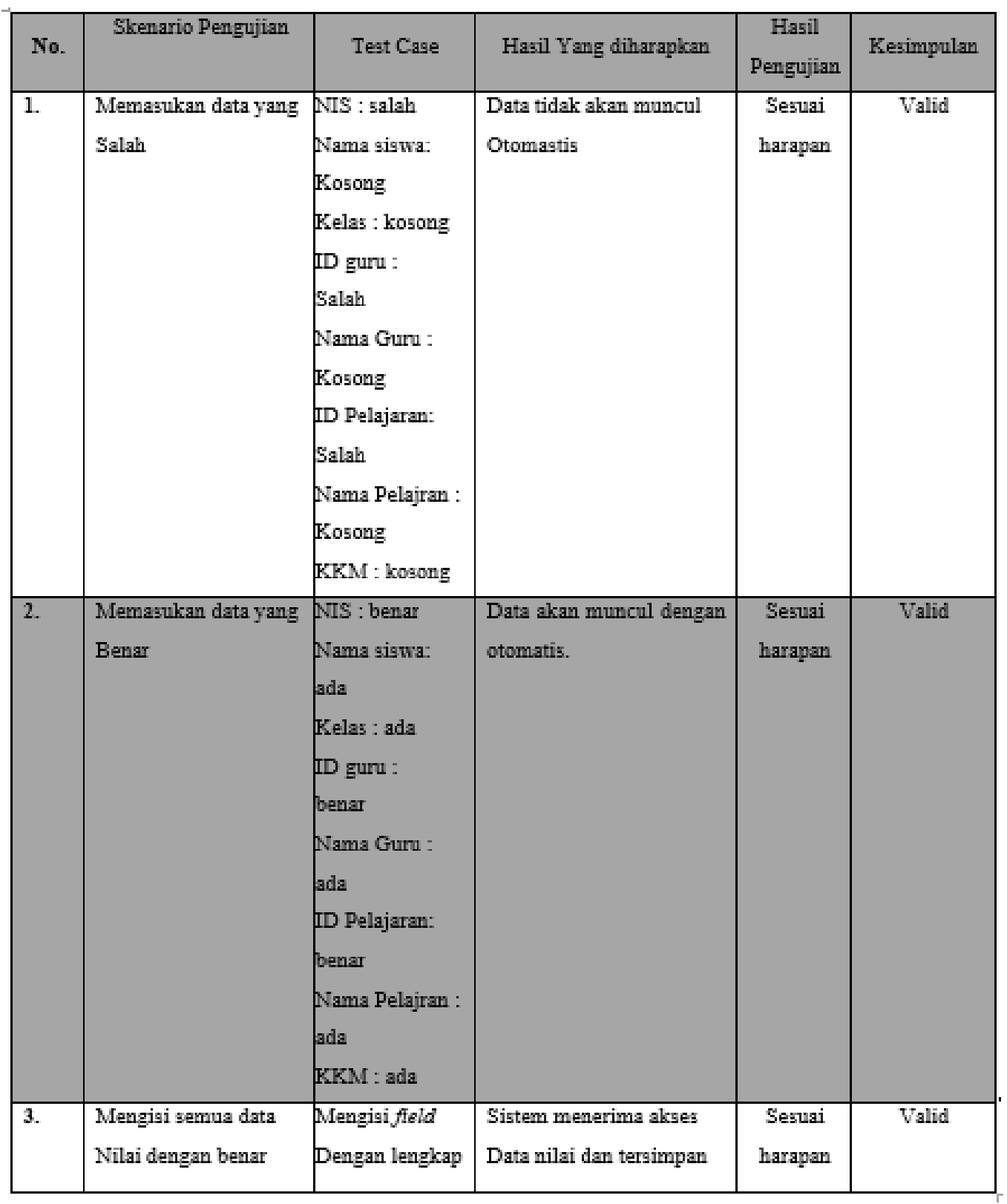

\section{KESIMPULAN}

Berdasarkan hasil pengujian terhadap aplikasi pengolahan nilai siswa, maka dapat diambil kesimpulan sebagai berikut:

1) Dengan program pengolahan nilai ini, memudahkan guru wali kelas dalam mengolah nilai siswa.

2) Mengurangi permasalahan keterlambatan dalam pengolahan data nilai siswa
3) Program ini dirancang atau dibuat untuk memudahkan setiap guru dalam membuat laporan nilai baik persemester ataupun tahunan.

4) Melihat dari aspek sistem, perawatan komputer sebaiknya dilakukan secara rutin agar tidak terjadi masalah ketika komputer digunakan dan melakukan backup database setiap akhir semester agar data tersimpan dengan baik.

5) Melihat dari aspek manajerial, diperlukan penelitian lebih lanjut tentang sistem informasi pengolahan data nilai siswa 
agar proses pengolahan nilai semakin berkembang dengan teknologi informasi yang lebih mutakhir.

6) Melihat dari spek penelitian selanjutnya, untuk penelitian lanjutan agar difokuskan pada pembuatan software yang lebh cangih dan sumber daya manusia yang lebih terlatih supaya proses pengolahan data nilai siswa lebih baik

\section{REFERENSI}

[1] Wibowo, Akhmad Luqman. (2013). Perancangan Sistem Informasi Pengolahan Nilai Siswa Pada SMP N 4 Jepara Berbasis Internet. Seminar Riset Unggulan Nasional Informatika dan Komputer FTI UNSA. Vol.2 No.1:2302-1136.

[2] Tan, Kim. (2017). Mengenal 3 Jenis Komputer, Fungsi Kelebihan dan Kekurangan. https://www.karyatekno.com/2017/04/mengenal-3-jeniskomputer-fungsi-kelebihan-dan-kekurangan/, 06 Desember 2018.

[3] Wardani, S.K. (2013). Sistem Informasi Pengolahan Data Nilai Siswa Berbasi Web Pada Sekolah menengah Kejuruan (Smk) Pgri I Pacitan Indonesian Jurnal on Networking and Security, 2(2), 2302-5700.

[4] Kusrini dan Koniyo, Andri (2007). Tuntunan Praktis Membangun Sistem Informasi Akuntansi dengan Visual Basic dan SQL Server. Yogyakarta : Andi Offset.

[5] Budi, Ronald. (2010). Programming With Microsof Visual Basic 6. Malang.

[6] Simarmata, Jenner, dan Iman Paryudi. 2010. Basis Data. Yogyakarta:Andi.

[7] Kusrini dan Koniyo, Andri (2007). Tuntunan Praktis Membangun Sistem Informasi Akuntansi dengan Visual Basic dan SQL Server. Yogyakarta : Andi Offset.

[8] Frieyadie (2007). Belajar Sendiri Pemrograman Database Menggunakan Foxpro9.0. Jakarta : PT. Elex Media Komputindo

[9] Booch, G., Maksimchuk, R. A., Engle, M. W., Young, B. J., Conallen, J., \& Houston, K. A. (2007). Object-Oriented Analysis and Design with Applications 3rd edition. Boston: Pearson Education.

[10] Widodo, Prabowo Pudjo dan Herlawati. 2011. Menggunakan UML. Bandung: Informatika Bandung.

[11] Rosa A.S., \& Salahuddin, M. (2013). Rekayasa Perangkat Lunak Terstruktur dan Berorientasi Objek. Bandung: Informatika.

[12] Apriyanto (2015). Analisa Dan Perancangan Pengolahan Nilai Siswa SMP Setia Budi Sungailiat Dengan VB.Net, Jurnal Sifom STMIK Atma Luhur Pangkalpinang.

[13] Laudon, Kenneth C., \& Jane, P. Laudon. (2010). Manajemen Information System :Managing the Digital Firm. New Jersey: Prentice-Hall

[14] Serfika, apriyani, H., Alawiyah, E. T. (2017). Perancangan Sistem Informasi Pengolahan Nilai Berbasis Web Pada Mts. Al Ghazaly Bogor. Jurnal Manajemen Dan Informatika Pelita Nusantara.

[15] Mustaqbal, M. S., Firdaus, R. F., \& Rahmadi, H. (2015). Pengujian Aplikasi Menggunakan Black Box Testing Boundary Value Analysis. Jurnal Ilmiah Teknologi Informasi Terapan. 